Alais Souza Ferreira, Larissa Fontoura Berlato,

Luiz Fernando Figueiredo, Gilson Braviano *

\title{
Pesquisa-ação: relações com o design
}

Alais Souza Ferreira é graduada em Design com habilitação em Design Gráfico da Universidade do Vale do Itajaí (UNIVALI - 2014), especialista em Marketing Criativo da UNIVALI (2017), mestre em Design pela Universidade Federal de Santa Catarina (UFSC - 2019) e, atualmente, doutoranda no Programa de Pós-Graduação em Design (Pós-Design) da UFSC. É bolsista CAPES e pesquisadora no Núcleo de Abordagem Sistêmica do Design (NASDesign) da UFSC desde 2017, atuando nas áreas de Gestão de Design, Abordagem Sistêmica, Ludificação, Gamificação e Pesquisa-ação. Juntamente com seu orientador, ministrou em 2018/1 a disciplina de Stop Motion para o curso de graduação em Animação no CCE/UFSC. <alais.ferreira@live.com> ORCID: 0000-0001-6071-0205
Resumo A pesquisa-ação é uma estratégia metodológica da pesquisa social que visa a ação como uma intenção de mudança. Essa ação consiste em resolver ou, pelo menos, esclarecer os problemas da situação observada. Esse método pretende envolver diretamente os grupos sociais na busca de soluções para seus problemas e promove uma maior articulação entre a teoria e a prática na construção de novos saberes. O presente artigo objetiva identificar as possíveis contribuições da pesquisa-ação nos processos de design, se caracterizando como um estudo qualitativo, exploratório e descritivo. Estabelece-se, ao final, que a pesquisa-ação pode contribuir para auxiliar o designer na compreensão do contexto; na identificação das necessidades dos atores envolvidos e dos problemas de uma determinada situação; na seleção de técnicas e ferramentas a serem utilizadas no processo; no diálogo entre todos os atores; na análise e interpretação das informações coletadas; e na formulação de uma solução de forma colaborativa ou cocriativa.

Palavras chave Investiga-ação, Pesquisa-ação, Design. 
Larissa Fontoura Berlato é graduada em Comunicação Social - Publicidade e Propaganda pela Universidade Federal do Rio Grande do Sul (2001), mestre em Design pela UFSC (2019) e, atualmente, doutoranda em Design pelo Pós-Design da UFSC. É pesquisadora no NASDesign da UFSC, atuando nas áreas de Gestão de Design, Abordagem Sistêmica, Design de Serviço, Sustentabilidade, Pesquisa-ação e Inovação Social. Juntamente com seu orientador, ministrou em 2018 a disciplina de Design e Sustentabilidade para a graduação em Design e Design de Animação no CCE/UFSC. Possui experiência empresarial nas áreas de Design Gráfico, Design de Produto, Gerência e Direção de Criação.<lari.berlato@gmail.com> ORCID: 0000-0002-2900-8626

\section{Action-research: relations with design}

Abstract Action research is a methodological strategy of social research that aims action as an intention to change. This action consists of solving or at least clarifying the problems of the observed situation. This method intends to directly involve social groups in the search for solutions to their problems and promotes a greater articulation between theory and practice in the construction of new knowledge. The present article aims to identify the possible contributions of action research in the design process, being characterized as a qualitative, exploratory and descriptive study. This analysis suggests that action research can help to assist the designer in understanding the context; in identifying the needs of the actors involved and the problems of a given situation; in the selection of techniques and tools to be used in the process; in dialogue among all actors; in the analysis and interpretation of the information collected; and in the formulation of a solution in a collaborative or co-creative manner.

Keywords Action-investigate, Action-research, Design.

\section{Investigación-acción: relaciones con diseño}

Luiz Fernando Gonçalves de Figueiredo É graduado em Engenharia Sanitária pela Universidade Federal de Mato Grosso (UFMT), mestre em Engenharia Civil pela UFSC, doutor em Engenharia de Produção pela UFSC, e pós-doutor em Tecnologia Ambiental pela UFMT. É professor no departamento de Design e Expressão Gráfica da UFSC e do Programa de Pós-graduação em Design da UFSC. Coordena o NAS Design/UFSC e como pesquisadores $\mathrm{CNPq}$, possui experiência na área de Gestão de Design, Abordagem Sistêmica e Design, com ênfase em Design Gráfica, Design de Produto, Pesquisa-ação e Inovação Social, especificamente com informação e sustentabilidade em produto e processo. Faz parte do grupo de avaliadores do INEP/MEC.

<lffigueiredo2009@gmail.com>

ORCID: 0000-0002-3327-9170
Resumen La investigación-acción es una estrategia metodológica de investigación social que tiene como objetivo la acción como una intención de cambio. Esta acción consiste en resolver o al menos aclarar los problemas de la situación observada. Este método pretende involucrar directamente a los grupos sociales en la búsqueda de soluciones a sus problemas y promueve una mayor articulación entre la teoría y la práctica en la construcción de nuevos conocimientos. Este artículo tiene como objetivo identificar las posibles contribuciones de la investigación de acción en los procesos de diseño, caracterizarse como un estudio cualitativo, exploratorio y descriptivo. Se establece, al final, que la investigación de acción puede contribuir a ayudar al diseñador a comprender el contexto; identificación de las necesidades de los actores involucrados y los problemas de una situación determinada; en la selección de técnicas y herramientas que se utilizarán en el proceso; diálogo entre todos los actores; en el análisis e interpretación de la información recopilada; y en la formulación de una solución de forma colaborativa o cocreativa.

Palabras clave Investigación-acción, Investigación-acción, Diseño. 
Gilson Braviano é Doutor em Matemática Aplicada pela Université Joseph Fourier, Mestre em Engenharia de Produção pela UFSC e Licenciado em Matemática pela UFSC. Desde 1995, trabalha no Departamento de Expressão Gráfica da UFSC, integrando a classe titular e atuando em disciplinas como Desenho Geométrico, Geometria Descritiva, Métodos de Representação e Métodos de Pesquisa. Trabalhou por seis anos na Pró-Reitoria de Cultura e Extensão e é docente permanente no Mestrado e Doutorado em Design da UFSC. É editor da RBEG (Revista Brasileira de Expressão Gráfica) e integra, no INEP/MEC, o Banco de Avaliadores das Instituições Brasileiras de Ensino Superior.<gilson@cce.ufsc.br> ORCID: 0000-0002-7967-2015

\section{Introdução}

A investigação-ação é uma metodologia que surgiu aproximadamente na metade do século XX e se estabeleceu primeiramente nas áreas médicas e de ciências sociais. Porém, aproximadamente em 1990, a investigação-ação se popularizou e passou a ser aplicada nas ciências da educação, voltada para a investigação em sistemas de informação e para a aprendizagem das organizações. Os primeiros a utilizarem esse método em suas pesquisas foram: Kurt Lewin (1946), que buscava integrar as minorias à sociedade nos Estados Unidos da América durante a pós-guerra; e o instituto Tavistock, que estudou as desordens psicológicas e sociais entre os veteranos da guerra (GRABAUSKA; BASTOS, 1998).

Pode-se definir a investigação-ação como uma metodologia de pesquisa, estabelecida por fundamentos pós-positivistas, que enxerga a ação como uma intenção de mudança e a investigação como um processo de compreensão (HUGON; SEIBEL, 1986). Dessa forma, é notável que tal metodologia articula teoria e prática no processo de construção do conhecimento e possibilita ao pesquisador uma atuação efetiva e participativa sobre a realidade estudada (FONTANA, 2014).

A investigação-ação objetiva transformar a realidade e produzir os conhecimentos que dizem respeito às transformações realizadas (HUGON; SEIBEL, 1986). Além disso, segundo Grabauska e Bastos (1998), devido à ação prática, o método tem produzido relevantes resultados na resolução de problemas, além de auxiliar os seres humanos a interpretar a realidade a partir de suas próprias práticas, concepções e valores. Lewin (1946) informa que a elaboração mais utilizada nos trabalhos de investigação-ação é a espiral autoreflexiva, constituída por três fases, compondo um ciclo de planejamento, um de ação e outro de averiguação de fatos referentes ao resultado da ação.

Segundo Tripp (2005), a pesquisa-ação é um dos inúmeros tipos de investigação-ação, que é um termo genérico para qualquer processo que siga um ciclo no qual se aprimora a prática pela oscilação sistemática entre agir no campo da prática e investigar a respeito dela. De acordo com Costa (1991), Lewin também usava o termo pesquisa-ação para descrever um processo de investigação que se move numa permanente espiral de ação-reflexão, uma vez que ele considerava possível captar as leis gerais da vida dos grupos por meio da observação e reflexão acerca dos processos de mudança social comunitária.

Kurt Lewin também é um dos principais precursores da pesquisa-ação, por seus estudos organizacionais e educacionais. Defensor de uma mudança social positiva, Lewin tinha muito interesse na relação da justiça social e na investigação rigorosa. Lewin desenvolveu a pesquisa-ação visando resolver dois problemas levantados pela sociedade em sua época: os problemas sociais e a necessidade de pesquisa. Quase imediatamente depois de Lewin haver cunhado o termo na literatura, a pesquisa-ação foi considera- 
da um termo geral para quatro processos diferentes: pesquisa diagnóstico, pesquisa participante, pesquisa empírica e pesquisa experimental (CHEIN; COOK; HARDING, 1948).

Alguns autores, dentre eles Demo (1995) e Le Boterf (1985), não fazem distinção entre pesquisa participante e pesquisa-ação. Por outro lado, Thiollent (2005) as diferencia. Segundo esse autor, a pesquisa-ação, além da participação, supõe uma ação planejada (social, educacional, técnica, entre outras) que nem sempre se encontra em propostas de pesquisa participante. Para ele, todo tipo de pesquisa-ação é do tipo participativo, pois a participação das pessoas implicadas nos problemas investigados é absolutamente necessária; mas nem toda pesquisa participante é pesquisa-ação. Contudo, esses autores coincidem na afirmação de que tanto a pesquisa-ação quanto a pesquisa participante procedem de uma busca alternativa ao padrão de pesquisa convencional.

O termo design significa planejar, desenhar, criar, conceber. Design é, portanto, um processo, uma prática e um modo de pensar, sendo a palavra tanto um substantivo (um resultado) quanto um verbo (uma atividade). O "resultado" de um projeto de design pode ser conferido nos produtos e serviços. A "atividade" de design consiste em um processo de resolução de problemas, centrado no usuário (BEST, 2012). O processo de design começa pelo desenvolvimento de uma ideia, pode concretizar-se em uma fase de projeto e sua finalidade seria a resolução dos problemas resultantes das necessidades humanas (LÖBACH, 2001).

A pesquisa-ação tem sido utilizada como método no desenvolvimento de estudos referentes ao design, evidenciando-se as áreas de sistemas de gestão (SEIN et al., 2011; MOREIRA et al., 2018), serviço (MARQUES, 2017) e produto e sustentabilidade (CANONICA et al., 2016; MOREIRA et al., 2016; CORRÊA; SARMIENTO; PEREIRA, 2017). O Núcleo de Abordagem Sistêmica do Design (NAS Design) da Universidade Federal de Santa Catarina, SC, Brasil, conduz, desde 2006, pesquisas teórico-práticas na área de design, relacionadas à sustentabilidade por meio da pesquisa-ação. O NAS Design desenvolve projetos para comunidades criativas, grupos de pessoas que, de forma colaborativa, reorganizam os elementos do sistema sociotécnico, inventando e gerenciando soluções para seus próprios problemas (MANZINI, 2008). Entre as pesquisas desenvolvidas encontram-se estudos sobre a abordagem sistêmica da gestão de design em: inovação social (MUNIZ, 2009; BERLATO, 2019); design conectivo (SILVA, 2012; SILVA, 2018); gamificação (DALLAGNOL, 2016; FERREIRA, 2019); e processos projetuais (AROS, 2016).

Ao pesquisar sobre pesquisa-ação, percebeu-se que esta tem sido utilizada em pesquisas de design em variados contextos. No entanto, existe uma lacuna de pesquisa referente a como esta metodologia vem contribuindo para esses estudos, e quais as convergências entre as etapas de pesquisa-ação e os processos de design (FRAGA et al., 2018). Por isso, esta pesquisa objetiva identificar as possíveis contribuições da pesquisa-ação nos processos de design. Para tanto, este estudo primeiramente conceitua o design e descreve as etapas da pesquisa-ação. Posteriormente, evidencia as relações e as possíveis contribuições entre as áreas estudadas. 
Este estudo é caracterizado, por sua natureza, como pesquisa básica e teórica; pela abordagem, como qualitativo; pelos objetivos, como exploratório e descritivo, por buscar compreender as relações existentes entre as áreas mencionadas anteriormente e por se tratar de um tema ainda pouco explorado nas pesquisas de design (CRESWELL, 2010; GIL, 2010; VIRGILLITO, 2010). De acordo com os procedimentos técnicos, a pesquisa é classificada como bibliográfica, e constituída por um levantamento de dados secundários (CRESWELL, 2010; GIL, 2010; VIRGILLITO, 2010) por utilizar livros e artigos científicos publicados em bases de dados eletrônicos (como o Google Acadêmico e o repositório UFSC).

Este artigo está estruturado em cinco seções: a primeira é composta por uma breve introdução que contextualiza a temática; a segunda apresenta a origem, a definição, os objetivos e as etapas da pesquisa-ação; a terceira conceitua o design e apresenta os principais métodos dessa área; a quarta analisa as contribuições deste método no processo de design; e a quinta relata as considerações finais.

\section{Pesquisa-ação}

Pelo final do século XX, Deshler e Ewart (1995) conseguiram identificar seis principais tipos de pesquisa-ação desenvolvidas em diferentes campos de aplicação. No final da década de 1940 e no início de 1950, utilizava-se em administração, desenvolvimento comunitário (LEWIN, 1946), mudança organizacional (LIPPITT; WATSON; WESTLEY, 1958) e ensino (COREY, 1949, 1953). Em 1970 incorpora-se com finalidades de mudança política, conscientização e outorga de poder (FREIRE, 1982), pouco depois, em desenvolvimento nacional na agricultura (FALS BORDA, 1986) e, mais recentemente, em negócios bancários, saúde e geração de tecnologia, via Banco Mundial e outros (HART; BOND, 1997).

O desenvolvimento desta modalidade de pesquisa intensificou-se fortemente no Brasil, entre 1980 e 1990, com as obras de René Barbier e Michel Thiollent, que são amplamente referenciadas. O surgimento de metodologias de pesquisa participativa relaciona-se à insatisfação com paradigmas e métodos de pesquisa clássicos e, no caso da pesquisa-ação, remete à necessidade de envolver diretamente os grupos sociais na busca de soluções para seus problemas e de promover maior articulação entre teoria e prática na produção de novos saberes (LEWIN, 1946; CARR; KEMMIS, 1986; THIOLLENT, 2005; BARBIER, 2002; EL ANDALOUSSI, 2004).

A pesquisa-ação é uma estratégia metodológica da pesquisa social com base empírica, na qual, segundo Thiollent (2005), há uma ampla e explícita interação entre pesquisadores e pessoas implicadas na situação investigada. Dessa interação resulta a ordem de prioridade dos problemas a serem pesquisados e das soluções a serem encaminhadas sob forma de ação concreta. O objetivo de investigação é constituído pela situação social e pe- 
los problemas de diferentes naturezas encontrados; visando resolver ou, ao menos, esclarecer os problemas observados. Durante o processo, há um acompanhamento das decisões, das ações e de toda a atividade intencional dos atores que estão envolvidos de modo cooperativo ou participativo. A pesquisa-ação não se limita a uma forma de ação (risco de ativismo), pretende aumentar o conhecimento dos pesquisadores e o conhecimento ou o nível de consciência das pessoas e grupos considerados.

Entre os objetivos de conhecimento potencialmente alcançáveis em pesquisa-ação, podemos identificar, segundo Thiollent (2005), a coleta de informação original acerca de situações ou de atores em movimento; a concretização de conhecimentos teóricos, obtida de modo dialogado na relação entre pesquisadores e membros representativos das situações ou problemas investigados; a comparação das representações próprias aos vários interlocutores; a fusão entre os saberes formal e informal acerca da resolução de diferentes tipos de problemas; a produção de guias ou de regras práticas para resolver os problemas e planejar as correspondentes ações; os ensinamentos positivos ou negativos quanto à conduta da ação e suas condições de êxito; possíveis generalizações estabelecidas a partir de várias pesquisas semelhantes e o aprimoramento de experiência dos pesquisadores.

A pesquisa-ação é caracterizada pela colaboração e negociação entre especialistas e práticos. Gil (1995) considera que, por meio do processo de pesquisa e intervenção, as pessoas envolvidas em determinada problemática e que participam da busca de soluções beneficiam-se com os resultados da pesquisa e, também, durante seu desenvolvimento, o que é próprio dessa metodologia. No decorrer desse processo, constroem-se conhecimentos individuais ou coletivos, novas habilidades e atitudes que propiciarão a ressignificação de valores e a transformação de situações indesejadas. Pimenta (2005) considera que na pesquisa-ação os sujeitos envolvidos em determinada problemática constituem um grupo com objetivos comuns, no qual assumem diversos papéis, inclusive como pesquisadores. Na interação pesquisador-pesquisado, ocorre a integração dos diferentes saberes e posições que eles possuem, sem diferenciação hierárquica. No quadro profissional, a pesquisa é conduzida de modo que não seja predeterminação dos interesses dominantes da organização, mas um constante compromisso com a verdade e com a intercompreensão dos atores que se relacionam na situação investigada em que o pesquisador não é tendencioso. Neste contexto, o papel do pesquisador deve ser o de oferecer subsídios que propiciem a participação dos atores sociais envolvidos em todas as etapas e assegurar o rigor metodológico, o qual favorecerá o cumprimento dos objetivos propostos (instrumentais, educacionais, científicos, entre outros).

Segundo Tripp (2005), para que a participação seja positiva, a proposta de pesquisa-ação deve: tratar de assuntos de interesse mútuo; basear-se em um compromisso compartilhado de realização da pesquisa; permitir que todos os envolvidos participem ativamente da forma que desejarem; parti- 
lhar, o quanto for possível, o controle sobre os processos da pesquisa; produzir uma relação de custo-benefício benéfica para todos; e estabelecer procedimentos de inclusão para decisões relativas à justiça entre os participantes.

A pesquisa-ação como método agrega várias técnicas de pesquisa social, como as de coleta e interpretação dos dados, de intervenção na solução de problemas e organização de ações. Também abrange as técnicas e as dinâmicas de grupo para trabalhar com a dimensão coletiva e interativa na produção do conhecimento e programação da ação.

A diferença fundamental entre a pesquisa-ação e os métodos convencionais está no seu objetivo: melhorar e envolver para produzir mudanças operacionais, justas e sustentáveis. Portanto, um aspecto crucial da pesquisa-ação é a participação das pessoas que vivem na situação pesquisada ou que podem ser afetadas pelos resultados da ação.

Uma limitação no desenvolvimento desta metodologia é o tempo necessário para a efetivação das ações propostas. Ela não é recomendada em estudos, no qual haja um período razoavelmente restrito para atender às demandas suscitadas pela questão de pesquisa. Outra dificuldade encontrada é a manutenção da imparcialidade do pesquisador frente às discussões do grupo, ao estímulo da construção coletiva e à apuração dos resultados. A análise dos dados deve ser ética e não tendenciosa, ao alcance dos objetivos desejados na pesquisa, tendo em vista que os resultados emergentes do grupo eventualmente divergem do proposto pelo pesquisador.

\section{Etapas da Pesquisa-ação}

Contrariamente a outros tipos de pesquisa, o planejamento da pesquisa-ação é flexível e não segue uma série de fases ordenadas, de forma rígida. Assim, existem diversas etapas para organização e efetivação, e sua execução pode ocorrer de diversas formas. Há sempre um vaivém entre várias preocupações a serem adaptadas em função das circunstâncias e da dinâmica interna do grupo de pesquisadores, no seu relacionamento com a situação investigada (THIOLLENT, 2005).

Ao optar por este tipo de pesquisa, é necessário ter em mente o tempo que o pesquisador terá para desenvolvê-la, pois é imprescindível o cumprimento de todas as fases, não sendo possível realizar somente a fase de diagnósticos, pois o que caracteriza a pesquisa-ação é a mudança. $O$ estudo pode levar muito tempo, quando se pretende que os sujeitos da pesquisa realizem o levantamento de seus problemas e necessidades, pois diferente do refletir, o fazer torna-se mais difícil e custoso para os sujeitos (SOMMER; AMICK, 1984).

Essa metodologia é considerada um sistema aberto, isso porque diferentes rumos podem ser tomados no decorrer do desenvolvimento, em função das demandas encontradas. Porém, segundo Thiollent (2005), há um ponto de partida (fase exploratória) e um ponto de chegada (divulgação dos resultados), mas no intervalo haverá uma multiplicidade de caminhos, 
Fig 1. Etapas da pesquisa-ação Fonte: Berlato (2019), com base em Thiollent (2005) em função das diferentes situações diagnosticadas ao longo do processo. As fases estão divididas em 12 etapas, conforme ilustra a Figura 1, as quais são descritas na sequência com base em Thiollent (2005).

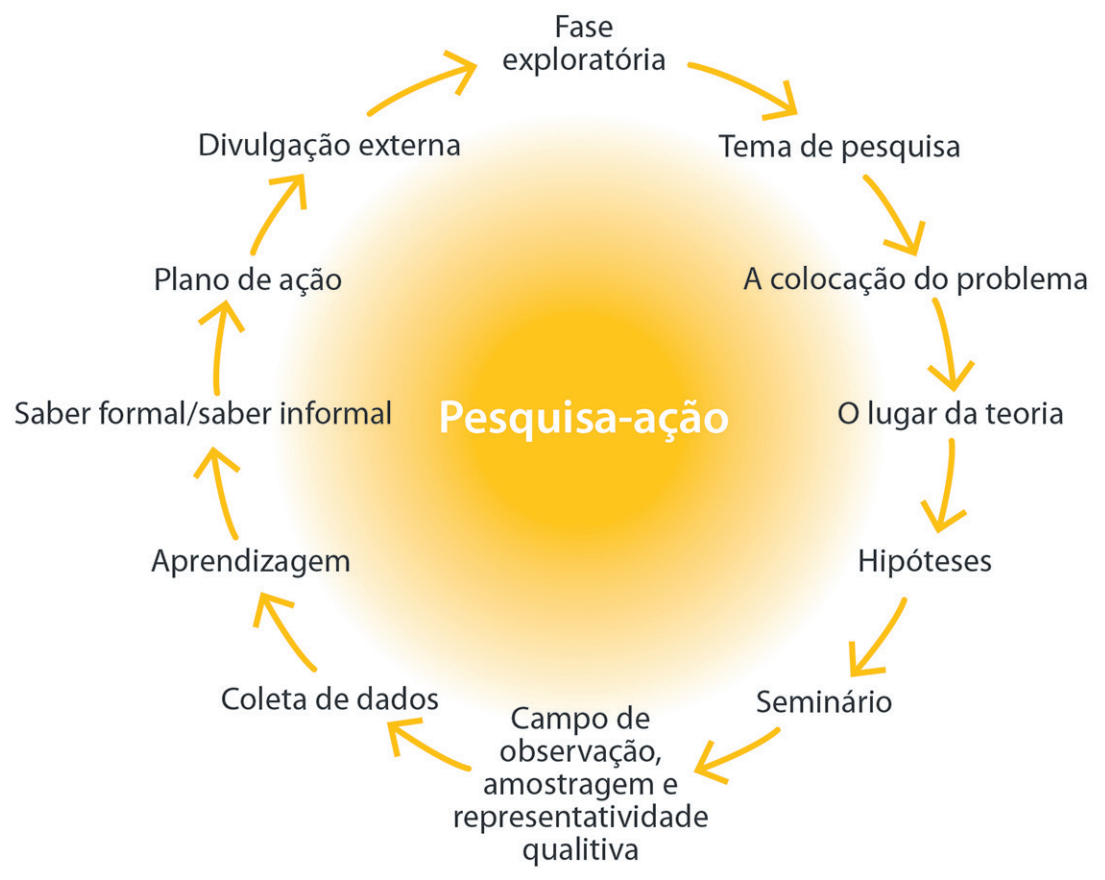

\section{Fase exploratória:}

Consiste em realizar um diagnóstico da realidade do campo de pesquisa, fazer os primeiros levantamentos da situação, dos problemas e de eventuais ações. Nos primeiros contatos com os atores envolvidos, a equipe de pesquisa tenta identificar as expectativas, os problemas da situação, as características da população e um reconhecimento de área, incluindo observação visual, consulta de mapas e organogramas, discussão direta com representantes diretos ou indiretos das várias categorias sociais implicadas e coleta de todas as informações disponíveis (documentação, jornais etc.).

Após o levantamento de todas as informações iniciais, os pesquisadores e participantes estabelecem os principais objetivos da pesquisa (referentes aos problemas considerados prioritários, ao campo de observação, aos atores e ao tipo de ação que estarão focalizados). De acordo com o princípio da participação, são destacadas as condições da colaboração entre pesquisadores e pessoas ou grupos envolvidos na situação investigada. 


\section{Tema de pesquisa:}

É a designação do problema prático e da área de conhecimento. 0 tema pode ser solicitado pelos atores e deve interessar ao pesquisador e aos sujeitos investigados, para que todos desempenhem um papel eficiente no desenvolvimento da pesquisa. Neste momento é escolhido um marco teórico para nortear a pesquisa.

\section{A colocação do problema:}

É a definição do principal problema, o qual é, inicialmente, de ordem prática. Trata-se de procurar soluções para se chegar a alcançar um objetivo ou realizar uma possível transformação dentro da situação observada. Na sua formulação, um problema desta natureza é colocado da seguinte forma:

a. Análise e delimitação da situação inicial;

b. Delineamento da situação final, em função de critérios de desejabilidade e factibilidade;

c. Identificação de todos os problemas a serem resolvidos para permitir a passagem de (a) a (b);

d. Planejamento das ações correspondentes;

e. Execução e avaliação das ações.

\section{0 lugar da teoria:}

É a etapa de realização do referencial teórico. O papel da teoria consiste em gerar ideias, hipóteses ou diretrizes para orientar a pesquisa e as interpretações. As informações que serão levadas ao seminário e a estratégia que faz parte do método devem ser interpretadas conforme esta teoria, dando rigor científico à pesquisa. A discussão teórica precisa ser compatível com o nível de entendimento dos participantes, podendo-se prever a organização de grupos de estudos separados do seminário central, cujas conclusões serão encaminhadas e discutidas em termos mais acessíveis.

\section{Hipóteses:}

Com base nas informações coletadas na pesquisa preliminar, passa-se, então, à formulação de uma ou mais hipóteses, a serem testadas. Uma hipótese é uma suposta resposta ao problema a ser investigado, tendo como papel fundamental na pesquisa a sugestão de explicações para os fatos. Essas sugestões podem vir a ser a solução do problema (GIL, 1995). A partir da formulação da hipótese, é preciso que o pesquisador identifique as informações necessárias, evite a dispersão, focalize determinados segmentos do campo de observação e selecione os dados. 


\section{Seminário:}

É onde se reúnem pesquisador e grupo de pesquisa, centralizando as informações recolhidas e discutindo o andamento da pesquisa. Tem a finalidade de coordenar as atividades do grupo, promover a discussão e a tomada de decisões acerca da investigação (definição de temas e problemas), constituir grupos de estudos, definir ações, acompanhar e avaliar resultados. 0 Seminário é sempre finalizado pela confecção de atas das reuniões que são as próximas diretrizes básicas de pesquisa e de ação submetidas à aprovação dos interessados, que são testadas na prática dos atores considerados.

\section{Campo de observação, amostragem e representatividade qualitativa:}

A delimitação do campo de observação empírica, no qual se aplica o tema da pesquisa, é objeto de discussão entre os interessados e os pesquisadores. Pode abranger uma comunidade geograficamente concentrada ou dispersa. A representatividade qualitativa é dada por uma avaliação da relevância política dos grupos e das ideias que veiculam dentro de certa conjuntura ou movimento. Trata-se de chegar a uma representação de ordem cognitiva, sociológica e politicamente fundamentada, com possível controle ou retificação de suas distorções no decorrer da investigação.

\section{Coleta de dados:}

É efetuada pelo pesquisador observador. 0 autor não limita a técnica de como serão coletados os dados, sejam quais forem elas, procura-se a informação que é julgada necessária, e da forma mais adequada ao andamento da pesquisa, desde que sejam definidas nos seminários. Algumas das principais técnicas utilizadas para a coleta de dados são as entrevistas, coletivas ou individuais; os questionários convencionais; os estudos de jornais e as revistas. Podem ser montados diversos grupos de observação e, para isso, faz-se necessário treinamento deste grupo. Todas as informações coletadas são transferidas ao seminário, para discussão, análise e interpretação.

\section{Aprendizagem:}

Na pesquisa-ação, uma capacidade de aprendizagem é associada ao processo de investigação, principalmente nos contextos das pesquisas em educação, comunicação e organização. As ações investigadas envolvem produção e circulação de informações, tomada de decisões, supondo uma capacidade de aprendizagem dos participantes; o pesquisador e os participantes aprendem algo ao investigar e discutir possíveis ações cujos resultados oferecem novos ensinamentos. Esta capacidade é aproveitada e enriquecida, já que ocorre uma aprendizagem conjunta. 


\section{Saber formal/saber informal:}

Faz parte da pesquisa-ação facilitar a comunicação entre os pesquisadores, técnicos e especialistas, que possuem universos culturais diferentes. De um lado, uma grande carga de saber formal e de outro de saber informal. Há uma interação entre o saber prático e o teórico, que se fundem na construção de novos conhecimentos. Busca-se a intercompreensão.

\section{Plano de ação:}

Para corresponder aos seus objetivos, a pesquisa-ação deve se concretizar em alguma forma de ação planejada, objeto de análise, deliberação e avaliação. Visa definir os atores, a relação entre eles, quem são os líderes, quais os objetivos e os critérios de avaliação da pesquisa, continuidade frente às dificuldades, quais estratégias serão utilizadas para assegurar a participação dos sujeitos, incorporação de sugestões e qual a metodologia de avaliação conjunta de resultados.

\section{Divulgação externa:}

Além do retorno da informação aos grupos implicados, também é possível, mediante acordo prévio, divulgar as informações externamente em diferentes setores interessados. A parte mais inovadora pode ser inserida em trabalhos e canais apropriados, como conferências, congressos, revistas etc.

\section{Design}

O design faz parte do desenvolvimento da economia intra e internacional, e está ligado às mudanças no ambiente digital e na macroeconomia. Por isso, essa disciplina "tem alguns efeitos indiretos sobre indicadores de concorrência internacional - tais como tecnologia, pesquisa e desenvolvimento (P\&D) e equilíbrio comercial de negócios -, mas também sobre o equilíbrio social, o bem-estar coletivo e os níveis de consumo de um país" (MOZOTA, 2011, p. 58).

O design não funciona isolado de outras disciplinas e profissões, mas associado a uma ampla variedade de condições. O contexto externo em que está inserido é evidente nas empresas, na sociedade, na tecnologia, na política e no ambiente. É evidente também em sua relação com os universos do marketing, da gestão, da engenharia, das finanças, do direito e da economia. Seu contexto interno inclui o modo como o branding e a inovação, a pesquisa de usuários e de mercado, os briefings de clientes e 
as auditorias de projeto, os orçamentos e as equipes, as metas e os objetivos de projeto podem ser alavancados para tirar o máximo proveito da atividade de design em prol das empresas, da sociedade e da economia. (BEST, 2012, p. 8).

Na visão de Best (2012, p. 12), o "design é um processo de resolução de problemas", uma prática e um modo de pensar, centrado nas pessoas. Infere-se que a atuação dessa área na sociedade abrange o modo como envolvemos os usuários nesse processo, que pode ser de forma colaborativa e participativa (codesign), como uma maneira de desenvolver produtos, serviços e sistemas. Essas abordagens permitem captar as necessidades dos atores, e o processo de design possibilita transformar "essas necessidades em proposições comerciais e soluções de design" (BEST, 2012, p. 28).

De acordo com a definição do International Council of Societies of Industrial Design - ICSID (2009), o design é fator central da humanização inovadora de tecnologias e o fator crucial de intercâmbio cultural e econômico, além de: descobrir e investigar as relações estruturais, organizacionais, funcionais, expressivas e econômicas, com o intuito de aumentar a sustentabilidade global e a proteção ambiental (ética global); prover benefícios e liberdade a toda comunidade humana, individual e coletiva, usuários finais, produtores e protagonistas de mercado (ética social); apoiar a diversidade cultural apesar do processo de globalização mundial (ética cultural); e fornecer produtos, serviços e sistemas, com aquelas formas que são expressivas (semiótica) e coerentes com sua complexidade (estética).

Neste contexto, evidencia-se que o design possui afinidade com a gestão por ser uma atividade de resolução de problemas, composta por um processo sistemático, lógico e ordenado (MOZOTA, 2011; BEST, 2012). Assim, segundo Mozota (2011), o conceito de design passa a envolver o processo: criativo interno; de produção externo; de gestão; e de planejamento. Destaca-se que no processo de design, após a identificação de um problema, "o designer segue um processo lógico, que ele aplica a cada fase do projeto" (MOZOTA, 2011, p. 27). Esse processo é uma habilidade aprendida, que corresponde ao uso de métodos, técnicas e ferramentas. Além disso, esse processo também é “iterativo, cíclico e não linear" (BEST, 2012, p. 46).

"O processo de design é um processo de conhecimento por meio do qual um design é adquirido, combinado, transformado e incorporado" (MOZOTA, 2011, p. 31). Esses processos possuem diversas similaridades, e Best (2012) agrupou seus aspectos comuns e os distribuiu em cinco fases fundamentais para o processo criativo de design: preparação; incubação; insight; avaliação e elaboração. Já Löbach (2001) estabeleceu o mesmo pensamento em quatro fases: análise; geração; avaliação e realização. Finalmente, para Mozota (2011) esse processo pode ser sintetizado em apenas três fases: análise (ampliação do campo de observação e verificação de informações); síntese (geração de alternativas); e solução (escolha da alternativa que solucione o problema). 
Além desses processos acima mencionados, podemos identificar o design thinking e o Hear, Create, Deliver (HCD), ambos criados pela IDEO (uma empresa internacional de design e consultoria em inovação). 0 design thinking é uma abordagem centrada no aspecto humano, destinada a resolver problemas e ajudar pessoas e organizações, por meio de um processo colaborativo que usa a sensibilidade e a técnica criativa para suprir as necessidades das pessoas, e possui três etapas: a inspiração, que utiliza o briefing, as observações, os registros e as documentações para descobrir as necessidades das pessoas; a ideação, que é o processo de síntese de todo o material documentado, incluindo a tradução das observações em insights que podem gerar soluções ou oportunidades de mudança; e a implementação, constituída pela formação de um plano de ação concreto com as melhores ideias geradas (prototipar, testar e iterar as ideias) e o estabelecimento de estratégias de comunicação (BROWN, 2010).

Segundo Pinheiro, Colucci e Melo (2009), o HCD foi desenvolvido para uso de organizações não governamentais que trabalham com comunidades locais em países em desenvolvimento, visando inovação social (produtos, serviços, ambientes, organizações e modos de interação). Seu processo também é constituído por três fases: ouvir (hear), etapa em que a equipe de design coletará histórias e se inspirará nas pessoas, esta também deve organizar e conduzir pesquisas de campo; criar (create), quando a equipe trabalha no formato de seminários para traduzir em estruturas, oportunidades, soluções e protótipos o que ouviu dos usuários, e durante essa fase o pesquisador passará do pensamento concreto ao abstrato, de forma a identificar temas e oportunidades para, mais tarde, voltar ao concreto com a criação de soluções e protótipos; e implementar (deliver), etapa composta pela implementação de soluções através de um sistema rápido de modelagem de custos e receitas, estimativas de capacitação e planejamento de implementação.

Assim, na sequência, estabelece-se uma discussão referente às contribuições da pesquisa-ação para o design.

\section{Contribuições da pesquisa-ação para o design}

A Figura 2 apresenta os processos de pesquisa-ação, segundo Thiollent (2005), e os processos de design, com base em Best (2012), Löbach (2001), Mozota (2011), Brown (2010) e IDEO (2009). A partir da análise desse quadro, podem-se identificar algumas similaridades e potencialidades quando da relação destes processos.

Ao comparar os processos, apresentados anteriormente, infere-se que tanto a pesquisa-ação quanto o design possuem fases para: compreender o contexto e fazer um planejamento; agir, implementar e desenvolver as ações planejadas; analisar essas ações, identificar as melhorias que elas proporcionaram ao contexto visando gerar aprendizado para todos os atores envolvidos e as questões que ainda podem ser aperfeiçoadas. 
Fig 2. Relações entre os processos de pesquisa-ação e de design Fonte: Elaborado pelos autores (2020) com base nos autores citados

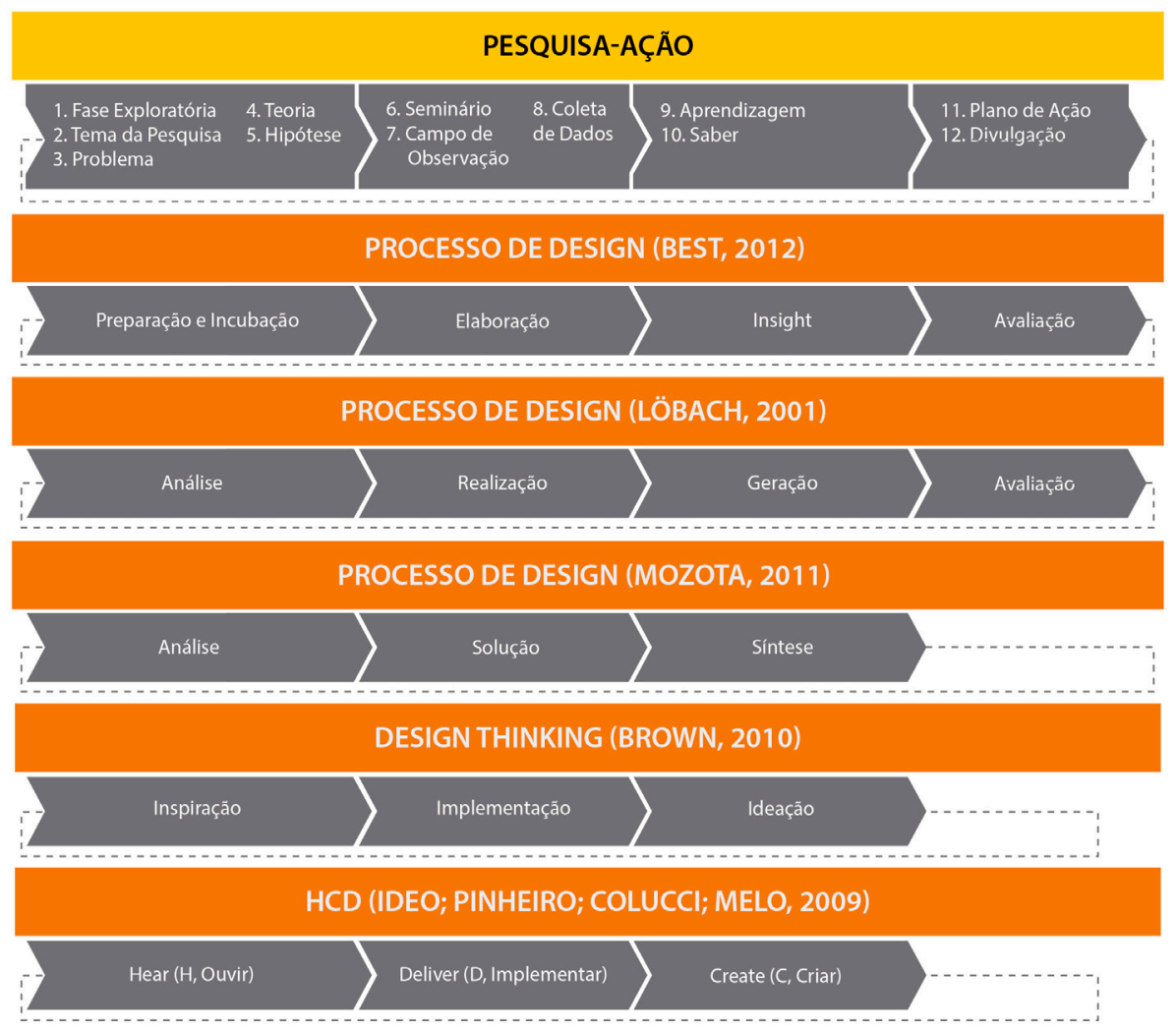

A pesquisa-ação é um método que agrega várias técnicas de pesquisa social, com os quais estabelece uma estrutura coletiva, participativa e ativa ao nível de captação de informações. Dessa forma, a pesquisa-ação pode contribuir positivamente em processos de design, auxiliando o designer na compreensão do contexto, na identificação das necessidades dos atores envolvidos e dos problemas de uma determinada situação.

0 design contemporâneo não considera o conhecimento como transferência de informações (conhecimento como substância), mas sim como processo de construção significativo e colaborativo (conhecimento como ferramenta). Então, o objetivo é aprender fazendo (aprendizagem cognitiva), a fim de propiciar um contexto para conversação e para a construção social de conhecimento. 0 design leva o conhecimento por meio de mudanças de processo, criatividade e dinâmica de trabalho em equipe (MOZOTA, 2011). Dessa forma, a pesquisa-ação pode trazer contribuições ao design por buscar construir os conhecimentos individuais e coletivos por meio da prática (ação) juntamente com a teoria (pesquisa), não se limitando a uma única forma de ação. Essa construção tem como intuito aumentar o conhecimento dos atores (pesquisadores e participantes) e grupos (comunidades e equipes) que estão envolvidos em um processo cooperativo ou participativo; resolver problemas no contexto da comunidade pesquisada, visando expandir essas soluções para outras situações semelhantes, por meio da produção de guias ou de regras práticas; e identificar os ensinamentos 
positivos ou negativos quanto à conduta da ação e suas condições de êxito, para poder planejar as próximas ações. Além disso, o processo de pesquisa-ação também contribui com a construção de novas habilidades e atitudes que propiciarão a ressignificação de valores e a transformação de situações indesejadas (THIOLLENT, 2005; GIL, 1995).

O design é uma cultura e uma prática relativas ao modo como as coisas deveriam ser, a fim de alcançar as funções e os sentidos desejados. $\mathrm{O}$ design tem lugar em processos abertos e cocriativos, nos quais todos os atores envolvidos participam de diferentes maneiras. Baseia-se em uma capacidade humana, que todos podem cultivar e que para alguns - os especialistas de design - se torna uma profissão. O papel desses especialistas é acionar e apoiar os processos abertos de codesign, usando o seu conhecimento para conceber e aprimorar iniciativas de design, claras e focalizadas (MANZINI, 2017). O codesign, na visão de Best (2012, p. 28), "é uma maneira de desenvolver produtos e serviços em parceria com vários stakeholders, captando as necessidades geradas pelos usuários e, por meio do processo de design, transformando essas necessidades em proposições comerciais e soluções de design". Assim, o design dá forma e viabilidade a novas ideias.

O conceito de codesign, de acordo com Manzini (2017), refere-se a um amplo e multifacetado diálogo entre uma multiplicidade de atores envolvidos na atividade de design; é um diálogo social entre diferentes atores, de diferentes maneiras e em diferentes momentos. Os processos de codesign são caracterizados por serem altamente dinâmicos, com atividades criativas e proativas, sendo o papel do designer um mediador entre diferentes interesses e um facilitador de ideias; e com atividades complexas de design, que demandam ferramentas específicas para visualização e prototipagem de ideias. Segundo Best (2012, p. 42), essas técnicas participativas e o codesign colaboram para os desafios sociais e para o design pela sociedade que aborda o "modo como envolvemos os usuários no processo de design".

Manzini (2008) ressalta o valor do conhecimento tácito presente nas pessoas da comunidade, envolvendo-as ao longo do processo, iniciando pela concepção, passando pelo desenvolvimento e chegando à aplicação. As pessoas são consideradas como possuidoras de capacidades que devem ser estimuladas para promover o bem-estar ativo e reforçar o tecido social.

A pesquisa-ação tem potencial para estabelecer um processo cocriativo, visto que, diferentemente da pesquisa convencional, a pesquisa-ação sempre pressupõe a participação e ação efetiva dos atores envolvidos. Este tipo de pesquisa social poderá contribuir no diálogo entre todos os atores, garantindo que as partes interessadas sejam ouvidas e integradas ao projeto em andamento, promovendo as habilidades e capacidades dos atores envolvidos e auxiliando na seleção de técnicas e ferramentas a serem utilizadas nos processos de codesign.

A pesquisa-ação está orientada em função da resolução de problemas, aumento de consciência ou de objetivos de transformação. Desta forma, poderá contribuir nos processos de design, na análise e interpretação das informações coletadas, e na formulação de uma solução de forma colaborativa e/ou cocriativa. 
Neste processo cocriativo, destaca-se a importância do novo papel do designer, como catalisador, conector, facilitador, visualizador e coprodutor de novos produtos, serviços, sistemas ou cenários possíveis (KUOSA et al., 2012; MANZINI, 2016).

Segundo Fraga et al. (2018), a utilização da pesquisa-ação no design pode "facilitar a interação com a comunidade; contribuir na explicitação das habilidades; compreender necessidades e desejos; e projetar estratégias participativas com o objetivo maior de trazer bem-estar para a coletividade". Isso pode ser evidenciado pela pesquisa de Moreira et al. (2018), na qual a implementação da pesquisa-ação permitiu observar a presença de fatores humanos e processuais nos âmbitos estratégico, tático e operacional da gestão de design.

\section{Considerações finais}

Este artigo objetivou esclarecer como a pesquisa-ação vem contribuindo para os processos de design, além de mostrar que as etapas desse método são similares as etapas do processo de design. A pesquisa-ação é um método que percebe a ação como uma intenção de mudança e a investigação ou pesquisa como um processo para compreender o contexto e o problema que está sendo estudado. Essa estratégia visa envolver diretamente os grupos sociais na busca de soluções para seus problemas e promover maior articulação entre a teoria e a prática na produção de novos saberes.

A pesquisa-ação tem potencial para contribuir positivamente nos processos de design, visto que constitui-se em uma pesquisa do tipo social que tem como objetivo a resolução de um problema coletivo, no qual os pesquisadores e os participantes estão envolvidos de modo colaborativo, beneficiando-se não só com os resultados da pesquisa, mas também durante seu desenvolvimento na integração dos diferentes saberes.

A partir de uma análise crítica sobre as áreas pesquisadas, disposta na seção quatro deste artigo, é possível inferir que a pesquisa-ação pode contribuir para auxiliar o designer: na compreensão do contexto; na identificação das necessidades dos atores envolvidos e dos problemas de uma determinada situação; na seleção de técnicas e ferramentas a serem utilizadas no processo; no diálogo entre todos os atores; na análise e interpretação das informações coletadas; e na formulação de uma solução de forma colaborativa ou cocriativa.

O presente estudo contribui teoricamente para o meio acadêmico por esclarecer as possíveis contribuições da pesquisa-ação para os processos de design, buscando preencher a lacuna de pesquisa evidenciada na pesquisa de Fraga et al. (2018). Destaca-se que este trabalho desenvolveu uma pesquisa exploratória que apontou diversos elementos de extremo interesse, e, por isso, sugere-se para futuras pesquisas a realização de uma revisão sistemática sobre os temas estudados. 


\section{Referências}

AROS, K. Elicitação do processo projetual do Núcleo de Abordagem Sistêmica do Design da Universidade Federal de Santa Catarina. Dissertação (mestrado), Programa de Pós-Graduação em Design e Expressão Gráfica, Universidade Federal de Santa Catarina, Centro de Comunicação e Expressão. Florianópolis, SC, 2016.

BARBIER, R. A pesquisa-ação. Brasília: Editora Plano, 2002.

BERLATO, L. F. A abordagem sistêmica da gestão de design na inovação social em uma unidade de conservação. 2019. Dissertação (Mestrado em Design) - Centro de Comunicação e Expressão, Programa de Pós-Graduação em Design, Universidade Federal de Santa Catarina, Florianópolis, 2019.

BEST, K. Fundamentos de gestão do design. Porto Alegre: Bookman, 2012.

BROWN, T. Design thinking: uma metodologia poderosa para decretar o fim das velhas ideias. Rio de Janeiro: Elsevier, 2010.

CANONICA, R.; PEIXE, R. P.; ANDRADE, I. T. de; COSTA, R. da. DZART: investigação acerca das possibilidades metodológicas do design e seu uso em processos de artesania. In: Congresso Brasileiro de Pesquisa e Desenvolvimento em Design, P\&D, 12., 2016, Belo Horizonte. Anais eletrônicos [...]. São Paulo: Blucher, 2016. DOI: 10.5151/despro-ped2016-0443. Disponível em: http://pdf.blucher.com.br.s3.amazonaws.com/designproceedings/ped2016/0443.pdf. Acesso em: 14 mar. 2019.

CARR, W.; KEMMIS, S. Becoming critical: education, knowledge and action research. London, Philadelphia: Palmer, 1986.

CHEIN, A.; COOK, S. W.; HARDING, J. The field of action research. American Psychologist, Washington, n. 3, p. 43-50, 1948. DOI: 10.1037/h0053515. Disponível em: https://psycnet.apa. org/record/1948-03013-001. Acesso em: 03 abr. 2019.

CORRÊA, G. R.; SARMIENTO, J.; PEREIRA, W. D. Contribuições do design para o bem estar social: o Programa CASOS-Catadores de Sonhos. Estudos em Design, Rio de Janeiro, v. 25, n. 2, p. 170-193, 2017. Disponível em: https://estudosemdesign.emnuvens.com.br/design/ article/view/490. Acesso em: 14 mar. 2019.

COREY, S. M. Action research, fundamental research and educational practice. Teachers College Record, Nova York, n. 50, p. 509-514, 1949.

COREY, S. M. Action research to improve school practices. Nova York: Teachers' College Press, 1953.

CoSTA, M. C. V. A caminho de uma pesquisa-ação crítica. Educação e Realidade, v. 16, n. 2, Porto Alegre, 1991.

CRESWELL, J. W. Projeto de pesquisa: métodos qualitativo, quantitativo e misto. Porto Alegre: SAGE, 2010.

DALLAGNOL, V. Como a gamificação pode contribuir no processo da gestão de design. 2016. Dissertação (Mestrado em Design) - Centro de Comunicação e Expressão, Programa de Pós-Graduação em Design, Universidade Federal de Santa Catarina, Florianópolis, 2016.

DEMO, P. Metodologia científica em Ciências Sociais. São Paulo: Atlas, 1995.

DESHLER, D.; EWERT, M. Participatory action research: tradition and major assumptions. Disponível em: http://www.PARnet.org/parchive/doc/deshler_95/. Acesso em: 28 mai. 1995. EL ANDALOUSSI, K. Pesquisas-ações: ciências, desenvolvimento, democracia. São Carlos: Edufscar, 2004. 
FALS BORDA, O. Conocimiento y poder popular: lecciones con campesinos de Nicaragua, México y Colombia. Bogotá: Siglo XXI, 1986.

FERREIRA, A. S. Ludificação e gamificação no processo de seleção de estratégia instrucional aplicada à gestão de design, associada à abordagem sistêmica e à prototipagem de serviço. 2019. Dissertação (Mestrado em Design) - Centro de Comunicação e Expressão, Programa de Pós-Graduação em Design, Universidade Federal de Santa Catarina, Florianópolis, 2019.

FONTANA, M. I. A investigação-ação e a relação teoria e prática na formação continuada de professores. 2014. Disponível em: http://www.uece.br/endipe2014/ebooks/livro2/A\%20 INVESTIGA\%C3\%87\%C3\%830-A\%C3\%87\%C3\%830\%20E\%20A\%20RELA\%C3\%87\%C3\%830\%20 TEORIA\%20E\%20PR\%C3\%81TICA\%20NA\%20FORMA\%C3\%87\%C3\%830\%20CONTINUADA\%2ODE\%20PROFESSORES.pdf. Acesso em: 13 jul. 2017.

FRAGA, P. G. R.; GIONGO, M. A.; MACEDO, L. F. de; SILVA, V. L. F. da; GUARIENTI, G. R.; LINDEN, J. C. de S. V. D.; RUTHSCHILLING, E. A.; JACQUES, J. J. de; BERNARDES, M. M. e S. Pesquisa-ação na pesquisa em design: uma análise das publicações da Design Studies de 1986 a 2017. In: LINDEN, J. C. de S. V. D.; BRUSCATO, U. M.; BERNARDES, M. M. e S. (Orgs.). Design em pesquisa. v. 2. Porto Alegre: Marcavisual, 2018. p. 523-540. Disponível em: https://www. lume.ufrgs.br/handle/10183/178694. Acesso em: 14 mar. 2019.

FREIRE, P. Creating knowledge: a monopoly. Nova York: Harper, 1982.

GIL, A. C. Métodos e técnicas de pesquisa social. São Paulo: Atlas, 1995.

GIL, A. C. Como elaborar projetos de pesquisa. São Paulo: Atlas, 2010.

GRABAUSKA, C. J.; BASTOS, F. Investigação-ação educacional: possibilidades críticas e emancipatórias na prática educativa. 1998. Disponível em: http://www2.uca.es/HEURESIS/heuresis98/ v1n2-2.html. Acesso em: 13 jul. 2017.

HUGON, M. A.; SEIBEL, C. (Orgs.). Recherches impliquées, recherches action: le recherches action cas de l'éducation: synthèse des contributions et des débats du colloque organisé par Institut National de la Recherche Pédagogique. Paris: INRP, 1986.

HART, E.; BOND, M. Action research for health and social care: a guide to practice. Buckingham: Open University Press, 1997.

KUOSA, T.; WESTERLUND, L.; INKINEN, S.; KOSKINEN, J. Service design: on the evolution of design expertise. 2012. Disponível em: https://www.theseus.fi/bitstream/handle/10024/51405/Kuosa_Tuomo_Lamk_2012.pdf. Acesso em: 06 ago. 2017.

LE BOTERF, G. Pesquisa participante: propostas e reflexões metodológicas. In: BRANDÃO, C. R. (Org.). Repensando a pesquisa participante. São Paulo: Brasiliense, 1985. p. 51-81.

LEWIN, K. Action research and minority problems. Journal of Social Issues, n. 2, p. 34-36, 1946. DOI: 10.1111/j.1540-4560.1946.tb02295.x.

LIPPITT, R.; WATSON, J.; WESTLEY, B. The dynamics of planned change. Nova York: Harcourt Brace, 1958.

LÖBACH, B. Design Industrial. São Paulo: Editora Edgar, 2001.

MANZINI, E. Design para Inovação Social e Sustentabilidade: Comunidades criativas, organizações colaborativas e novas redes projetuais. Rio de Janeiro: E-papers, 2008.

MANZINI, E. Design culture and dialogic design. Design Issues, v. 32, n. 1, p. 52-59, 2016. DOI: 10.1162/DESI_a_00364. Disponível em: https://www.mitpressjournals.org/doi/pdf/10.1162/ DESI_a_00364. Acesso em: 27 ago. 2017. 
MANZINI, E. Design: Quando Todos Fazem Design. São Leopoldo: Editora Unisinos, 2017. MARQUES, A. M. Possibilidades do design thinking para a implementação de serviços públicos inovadores: uma pesquisa-ação em gestão pública na Procuradoria-Geral da Fazenda Nacional. 2017. Dissertação (Mestrado em Administração Pública) - Centro de Formação Acadêmica e Pesquisa, Escola Brasileira de Administração Pública e de Empresas, Rio de Janeiro, 2017. Disponível em: https://bibliotecadigital.fgv.br/dspace/handle/10438/20598. Acesso em: 14 mar. 2019.

MOREIRA, B. R.; MOREIRA, M.; BERNARDES, S; ALMENDRA, R. A. Gestão do design na prática: discussão dos fatores humanos e processuais envolvidos. Gestão \& Tecnologia De Projetos, v. 13, n. 1, p. 59-74, 2018. DOI: 10.11606/gtp.v13i1.109576. Disponível em: http://www.journals.usp.br/gestaodeprojetos/article/view/109576. Acesso em: 14 mar. 2019.

MOREIRA, B. R.; MOREIRA, M.; BERNARDES, S; VAN der LINDEN, J. C. de S. Implementação simultânea de práticas de design em empresas desenvolvedoras de produtos. Estudos em Design, Rio de Janeiro, v. 24, n. 2, p. 44-65, 2016. Disponível em: https://www.eed.emnuvens. com.br/design/article/view/344/230. Acesso em: 14 mar. 2019.

MOZOTA, B. B. de. Gestão do design: Usando o design para construir o valor de marca e inovação corporativa. Porto Alegre: Bookman, 2011.

MUNIZ, M. O. A prática sistêmica do design em comunidades tradicionais locais como forma de promoção de inovações sociais: caso Guarda do Embaú. 2009. Dissertação (Mestrado em Design e Expressão Gráfica) - Centro de Comunicação e Expressão, Programa de Pós-graduação em Design e Expressão Gráfica, Universidade Federal de Santa Catarina, Florianópolis, 2009.

PIMENTA, S. G. Pesquisa-ação crítico colaborativa: construindo seu significado a partir de experiências com a formação docente. Educação \& Pesquisa, São Paulo, v. 31, n. 3, p. 521539, set./dez. 2005. DOI: 10.1590/S1517-97022005000300013. Disponível em: http://www. scielo.br/scielo.php?pid=S1517-97022005000300013\&script=sci_abstract\&tlng=pt. Acesso em: 03 abr. 2019.

PINHEIRO, T.; COLUCCI JR., J.; MELO, I. de. Human-Centered Design: kit de ferramentas. 2009. Disponível em: http://www.uxdesign.blog.br/pesquisa-com-usuarios/human-centered-design-kit-de-ferramentas/. Acesso em: 29 Ago. 2017.

SEIN, M. K.; HENFRIDSSON, O.; PURAO, S.; ROSSI, M.; LINDGREN, R. Action design research. MIS Quarterly, v. 35, n. 1, p. 37-56, mar. 2011. DOI: 10.2307/23043488. Disponível em: http:// citeseerx.ist.psu.edu/viewdoc/download?doi10.1.1.462.3275\&rep=rep1\&type=pdf. Acesso em: 14 mar. 2019.

SILVA, C. S. da. Abordagem sistêmica com foco na gestão de design sustentável: o caso Nuovo Design. 2012. Dissertação (Mestrado em Design e Expressão Gráfica) - Centro de Comunicação e Expressão, Programa de Pós-Graduação em Design e Expressão Gráfica, Universidade Federal de Santa Catarina, Florianópolis, 2012.

SILVA, C. S. da. Design conectivo: uma ferramenta sistêmica para identificação, mensuração, representação e avaliação de interações. 2018. Dissertação (Doutorado em Design) - Centro de Comunicação e Expressão, Programa de Pós-Graduação em Design, Universidade Federal de Santa Catarina, Florianópolis, 2018.

SOMMER, R.; AMICK, T. Pesquisa-ação: ligando pesquisa à mudança organizacional. [Série: Planejamento de Pesquisa nas Ciências Sociais. n.4]. Brasília: UnB; 1984. Disponível em: http://www.unb.br/ip/lpa/pdf/04Action.pdf. Acesso em: 17 jul. 2017.

THIOLLENT, M. Metodologia da pesquisa-ação. 16. ed. São Paulo: Cortez, 2005. 
TRIPP, D. Pesquisa-ação: uma introdução metodológica. Educação \& Pesquisa, v. 31, n. 3, p. 443-466, São Paulo, 2005. DOI: 10.1590/S1517-97022005000300009. Disponível em: http:// www.scielo.br/scielo.php?pid=S1517-97022005000300009\&script=sci_abstract\&tlng=pt. Acesso em: 03 abr. 2019.

VIRGILLITO, S. B. Pesquisa de marketing: uma abordagem quantitativa e qualitativa. São Paulo, SP: Saraiva, 2010. 